\title{
Micro-channel public platform in Bridge Engineering Course Teaching Reform
}

\author{
Chen Tie
}

Shijiazhuang Railway Institute, Shi Jiazhuang, China, 050043

Keywords: micro-channel public platform, bridge engineering, teaching

\begin{abstract}
The micro-channel public platform as a new thing in the field of information technology, social life had a huge impact. According to the features and benefits of the platform, the article discusses the micro-channel public platform "bridge project" Teaching the application possibilities and reality, analysis of the micro-channel public platform for this new teaching tool for the next intervention to solve the existing educational model some problem ways and means to point to an area, to speed up the micro-channel public platform as a teaching tool to get more in-depth promotion and application of the various disciplines in the field of higher education.
\end{abstract}

\section{The "Bridge Project" Teaching Situation Analysis}

"Bridge Project" is an important professional course compulsory civil engineering major bridge direction, plays a very important role in the curriculum system, the "Bridge Engineering" course mainly include various types of bridge structure design calculations, construction measures and construction technology, "bridge project" curriculum of knowledge involving relatively large, in addition to requiring teachers to have a high level of theoretical knowledge but also have some practical experience, while teaching level of teachers also have higher requirements. The quality of the teaching curriculum for training quality bridge direction of civil engineering specialty students a significant relationship. In recent years, through participation in teaching and research conference seminar with their own experience in the teaching process, I found that "Bridge Project" Course there is some problems to be solved, epitomized by the following:

a. Textbook content updates slowly, it lagged behind the development status of the bridge.

In recent years, to meet the country to build a comprehensive transportation system, strengthening the transportation infrastructure development needs, construction of bridge construction technology advances, new bridge structure system innovation, design theory bridge continuous improvement and development of new materials, new technology from research and development It came to be applied to the actual construction of the bridge become shorter and shorter. The pace of development in the areas of bridge engineering far beyond the pace of updates Bridge Engineering course materials. How to rapidly changing developments in bridge engineering and bridge-building results representative to teach students in a timely manner, which is in urgent need of an appropriate method will be updated with current information in a timely manner to the teaching content to go.

b. Practical arrangements for increasing the difficulty of teaching, practice teaching effect gradually weakened.

In recent years, by the provision of teaching practice, hours, construction units operating limitations and other factors, the difficulty increasing practice teaching arrangements, even if teaching plan can be implemented, often because of the tight schedule, a large number of students, so that most of the teaching process flow in the form of fly, teaching less desirable. Gradually weaken the role of teaching practice, so that students' theoretical knowledge is difficult to combine with the production practice, course contents of bridge engineering and construction principles of the more important aspects of the construction process of the lack of intuitive understanding, these problems will inevitably have a follow-up study courses and graduate students design aspects conducted a tremendous obstacles, and even affect the students' early career working adaptability.

c. Less effective teaching hours, teaching is not ideal. 
Currently, training in accordance with the respective engineering colleges mostly "thick foundation, wide caliber" mode, Bridge Engineering Courses Hours a certain degree of compression, the creation of the university theory teaching hours of bridge engineering courses is generally about 48 to 64 hours, now there are arrangements in relation to the hours of course very complex body of knowledge limited.

In the actual teaching process, but also because students are often on the basis of professional knowledge is not solid, the impact of prior knowledge inadequate reserves and other factors, the teachers in order to make the teaching content to form a more complete knowledge framework, had to spend a lot of time and effort to students explain the basic knowledge, teaching arrangements planned affected the effective teaching hours is further compressed, the content is too tight, affecting the effectiveness of teaching.

$\mathrm{d}$. The traditional teaching model is too dependent on teacher-led, not conducive to mobilizing the enthusiasm of students to participate.

Teachers are the leading teaching activities, students are the main teaching activities, the ideal is to construct a teaching model should both play a leading role of teachers can fully reflect the students' main role of the new teaching structure. In the traditional mode of teaching, more embodied in the leading role of teachers, teachers become the center of the structure of teaching, teachers are imparting knowledge, is active teaching, and teachers with curriculum based teaching curriculum content preparation and implementation, and monitor the whole process of teaching and learning activities. In this process, students are taught knowledge objects are passive recipients of external stimuli.

Traditional teaching model is completely dominated by the classroom teacher, ignoring the main role of students and teachers is more focused on "what to teach students to give their own knowledge," but often overlooked "Students really want to learn what knowledge", once ignored students' interest in learning, the teaching effect must be perceptibly the same time, this kind of teaching indoctrination, is not conducive to cultivate innovative thinking and creative ability of new talent.

e. The traditional assessment methods over a single, not conducive to the students practical, innovative culture.

Bridge engineering course examination of the most common form of the written examination is usually scheduled after the end of the courses, test scores is the standard displacement measured by student learning effect. Since "a test for the success of" particularity, examination papers are mostly law-abiding, not the basic outline of the scope of a breakthrough, even occasionally innovative questions arise, tend to be tasted.

Assessment mode about the way students learn, the traditional evaluation model, more memory and test a student's ability to recite, while ignoring the students' thinking ability test. At the national advocate and promote excellence in engineering program in the background, current teaching evaluation model is clearly unable to meet the needs of the new era of innovative talents.

\section{Micro-channel and development status}

Tencent micro-channel has developed an instant messaging software, it can transfer text and voice messages through the network, at the same time, can make use of micro-channel public platform to push images, audio, video files function. Since January 21, 2011 published, Tencent micro letter function continuously improved, so the number of users is also an alarming rate continues to grow, as after the 2013 Spring Festival, the micro-channel registered users has exceeded 400 million, mobile instant messaging software become Asia's largest user groups.

In recent years, with the lower prices of mobile phones and communications tariffs, covering a wide range of wireless network wifi smart phone it has become mainstream mobile phone, which has long been not just a simple communication tool, used more as a personal digital information terminals, particularly young college students, the smart phone has a very high utilization, micro letter also got the further development and popularization.

Tencent, according to official information, micro-channel users in the age distribution, the 20 to 
30 year-olds accounted for 72 per cent, from the point of view of the distribution of occupation, college students accounted for $64 \%$. As can be seen from the data analysis, the high-speed development in a post today, it has become a social movement of today's youth, especially to accept new things, new ways of social ability of the student population.

\section{The micro-channel platform in teaching reform}

How to take advantage of the high penetration rate of mobile phone "micro channel" terminal, to build an interactive platform to promote the teaching curriculum and improve the quality of teaching level, it has become a promising research topics and application value. The following I will "bridge project" Teaching Reform and to explore how to use the micro-channel public platform to establish specialized courses Interactive Teaching Mode.

a. To establish a "micro-classroom" platform to expand the depth and breadth of Teaching.

Micro-channel mobile phone terminal is open 24 hours a full-time, we use this feature micro-channel platform, the establishment of "micro-classroom" platform. In this "classroom" where teachers can break through the limitations syllabus, hours and materials, the new bridge theory in the field of new technologies and new results illustrated form or through audio, video and other multimedia forms pushed to students' mobile terminals.

Push content can be both theoretical concepts can also be construction technology; both macro can also be summarized detailed description. Therefore, not only the construction of expansion of theoretical knowledge "micro classroom" platform, but also a useful complement to the practice of teaching. Students at any time convenient to them, in the dormitory, playground, cafeteria, bus station or any occasion, you can open the micro-channel learning content you're interested in, like at any time exposure to an open campus, to create self-centered learning environment of space-time.

b. Construction of interactive teaching platform to improve student engagement in the teaching process.

The so-called "interactive" teaching model, education is to be seen as a kind of life of teachers and students to interact with life, communication, the teaching process as a teaching and learning dynamic development of unified interaction and interaction processes in this process, by optimizing the "interactive teaching" approach, that is, by adjusting the relationship between teachers and their interaction, to create a harmonious teacher-student interaction, students interaction, interactive learning and teaching individual intermediaries, strengthen human interaction with the environment effect to produce teaching resonance, to improve the teaching effect of a teaching structure model. The core of this teaching method is that smooth communication between teachers and students.

With the recent university enrollment, teachers often face a semester dozens or even hundreds of students, classroom exchange alone time is very limited. This is precisely the biggest problem hampering the effective implementation of interactive teaching.

Through micro-channel can overcome the limitations of time, overcome the limitations of place, teacher-student interaction can be extended to outside the classroom; teacher-student interaction can be sustained beyond 8 hours. Before class through interactive, students can learn to carry out pre-preliminary knowledge required to master the curriculum, teachers can understand students' curriculum points of interest, as a reference preparation courses; after-school through interactive, more students would be interested in the course content depth discussions with the teachers to work more, teachers can organize students to evaluate teaching effectiveness, teaching content and targeted form of bold reforms.

c. To explore a new way of course examination.

Assessment methods in colleges and universities, students will often form a "no after-school review, busy exam assault" bad study habits, is not conducive to improving the knowledge accumulated precipitation, and theoretical system. Quiz conducted after the end of each chapter teaching, assessment is an ideal way, but often limited to teaching hours, it is difficult to carry out.

Teacher Quiz through micro letter can be extended to the lower classes, while more open examination questions can be set, not rigidly adhere to materials, so that students have a greater degree of space to play, through access to information, etc., to further broaden their horizons and 
improve the depth and breadth of knowledge.

d. Advanced micro-channel functional application in teaching

With the further development of open micro-channel function, which play a more important role in teaching reform in colleges and universities. In the course under construction, teachers can upload courseware, model and other information on the micro-channel platform to build interactive dialogue style navigation menu, students can download the contents of self-interested in learning. Meanwhile custom micro-channel public platform also provides recovery capabilities, students can efficiently customize query information, advice frequently asked questions, or make personal problems, or automatically by the platform teacher manual reply. Micro-channel platform, users can classify teachers in the platform can push updated information to distinguish different students based on classification, quick notification will be teaching, teaching content, test scores and other content in a timely manner to inform each student's phone.

\section{The establishment of micro-channel interactive teaching platform of potential prospects}

Micro-channel public platform because of its ease of use, content push high timeliness and accuracy and other characteristics, in line with modern habits of young student population, and laid a good foundation for the promotion of micro-channel public platform. With the micro-channel software upgrade to improve a wide range of smart phones and the popularity of micro-channel public believe the platform will play a more important role in the teaching management.

\section{References}

[1] $\mathrm{Hu}$ Rui. Students use the micro-channel in University Teaching Prospect[J]. Beijing Youth Research, 2014, (01): 76-80.

[2] Kuang Wenbo. 2012 development of mobile media inventory[J]. Media, 2013 (1): 65-67.

[3] Li Huaqiong. Ideological and Political Education WeChat era Discussion[J]. School Party building and ideological education, 2013, (13): 63-65.

[4] Huangpu District, Beijing East Road Primary School. "Classroom Interaction" is "Paradise" type of basic teaching model school[J]. Shanghai education, 1997, (02): 7-10.

[5] Hu Mianyi, Du Jia. "Bridge Project" Teaching and Reform Countermeasures[J]. Chongqing Jiaotong University (Social Science Edition), 2002,2 (2): 87-88. 